\title{
Collaboration technology in teams and organizations: Introduction to the special issue
}

\author{
Gert-Jan de Vreede $^{1}$ - Pedro Antunes ${ }^{2}$. Julita Vassileva ${ }^{3}$ - Marco Aurélio Gerosa ${ }^{4}$. \\ Kewen $\mathrm{Wu}^{3}$
}

Published online: 8 February 2016

(C) Springer Science+Business Media New York 2016

\section{Introduction}

Information technology advances in recent years have facilitated new forms of information and knowledge sharing. Teams and organizations are increasingly exploring and adopting new technologies to support collaborative work. Such technologies range from collaboration and communication technologies that connect members of virtual teams across national and international boundaries to social media technologies that allow teams and organizations to disseminate and gather information from within and outside their institutional boundaries. The widespread availability of smart phones has given whole societies opportunities to participate

Kewen Wu

kew259@mail.usask.ca

Gert-Jan de Vreede

gdevreede@usf.edu

Pedro Antunes

Pedro.Antunes@vuw.ac.nz

Julita Vassileva

jiv@cs.usask.ca

Marco Aurélio Gerosa

gerosa@ime.usp.br

1 Information Systems and Decision Sciences Department, University of South Florida, Tampa, FL, USA

2 School of Information Management, Victoria University of Wellington, Wellington, New Zealand

3 Department of Computer Science, University of Saskatchewan, Saskatoon, SK, Canada

4 Department of Computer Science, University of São Paulo, São Paulo, SP, Brazil in large-scale sensemaking, problem solving, and efforts to organize collaborative action. Some of the more popular modern collaboration technologies that have been widely employed in organizations include wikis, social networks, crowdsourcing, tagging plugins, and mashups (Andriole 2010; Van Osch et al. 2015; Go and You 2016).

A wiki is a web-based application that allows users to collaboratively develop and modify web pages. The most wellknown example of a wiki is Wikipedia, the online encyclopedia that has been developed and maintained by thousands of volunteers for over 15 years. A wiki system can facilitate knowledge acquisition and support collaboration and communication among members of an organization. Specifically, wikis have the potential to serve as dynamically evolving organizational knowledge repositories by harvesting fragmented knowledge contributed by users. Compared to traditional knowledge management systems (KMSs), wiki systems put less emphasis on centralized control, strict discipline, and extensive monitoring, while users do not need to possess significant technical expertise to participate in the contribution process (Hasan and Pfaff 2006). Experiences with the organizational application of wikis have shown that although wikis require constant contributions to ensure sustainability, they provide a low-cost solution to knowledge management in terms of the creation and deployment of knowledge repositories (Almeida and Rocha 2011; Standing and Kiniti 2011; Arazy and Gellatly 2012). Furthermore, studies suggest that wikis are more effective in facilitating tacit and informational knowledge sharing among organization members than traditional KMSs (Cress and Kimmerle 2008; Standing and Kiniti 2011).

Organizations can employ social network technologies both internally and externally. Using internal social networks, individuals can shorten their learning cycle by exploring shared experiences of colleagues (Lin and Hsueh 2006). 
Moreover, internal social networks can circumvent bureaucratic boundaries and facilitate information sharing activities among individuals across hierarchies and divisions or departments. This has shown potential for high levels of group productivity (L. Wu 2013). External social networks can also be of significant value to organizations. For example, an organization may open a channel to the public and invite consumers and other stakeholders to participate in the whole production process, ranging from product development to brand management (Garrigos-Simon et al. 2012). This allows organizations to acquire resources or competencies from external sources that otherwise would be difficult or expensive to access (Seyff et al. 2015) .

Crowdsourcing is also increasingly attracting attention from both organizations and scholars (Pedersen et al. 2013). Crowdsourcing is a collaboration model enabled by social web technologies to solve organizational problems in partnership with online communities (Oh et al. 2012). It is a special form of outsourcing in which a job traditionally performed by organizational employees is outsourced to an undefined, generally large group of people in the form of an open call (Howe 2008). There are different crowdsourcing models, including virtual labor markets (e.g., Amazon's Mechanical Turk), idea competitions (e.g., Innocentive), and community crowdsourcing, in which participants discuss issues relevant to their community (e.g., MindMixer). Experiences show that crowdsourcing may provide a low cost and scalable way to access ideas that might be difficult or expensive to obtain internally (Cox 2011; Majchrzak and Malhotra 2013). Furthermore, it can reduce bias in collective decisionmaking compared to small teams due to the crowd's diversity of opinions, assumptions, and beliefs (Bonabeau 2009). The labor cost paid for freelancers in a virtual crowdsourcing marketplace is much lower than that for professionals for the same tasks (Howe 2008). Governments and public organizations are attracted to the idea of engaging with online citizens, since it has the potential to increase the novelty and relevance of ideas and solutions, commitment of the citizens to accept changes, and government transparency (Brito 2008; Bommert 2010). As a result, organizations are able to focus more on their own areas of competence and gain a competitive advantage by acquiring richer content and better solutions in a creative and cost-effective way (Zhao and Zhu 2012).

While wikis, social networks, and crowdsourcing represent platforms or strategies adopted by organizations, tags and mashups are often considered as collaboration add-ons to other systems. Tags are keywords generated by users in order to classify and index a given resource. Tags can be keywords that occur in a resource, or users' own words. Experiences with tagging show that the tagging feature embedded in other systems (e.g., a software development platform) is useful to mark important pieces of information for future navigation and an effective asynchronous communication mechanism to support geographically distributed group members (Storey et al. 2006). Moreover, by using Really Simple Syndication (RSS) aggregators, users can promptly receive material marked by tags of interest from many sources. Thus, knowledge sharing efficiency is improved (Hong et al. 2011).

A mashup is the merging of online services from multiple providers in an integrated way (Auinger et al. 2009). For example, FireMash, a system used to report bushfires in Australia, combines live Twitter and RSS posts from the New South Wales Rural Fire Service and pinpoints their locations on a map (Vivacqua and Borges 2012). Organizations have reported that many unforeseen and short-term requirements can be raised during a collaboration process. However, current organizational operation systems cannot respond to such dynamic requirements in terms of investment costs and time-constraints of development or integration. As a result, knowledge workers usually stop using official applications and start to use small ad hoc applications (Soriano et al. 2010; Bader et al. 2012). Mashups support organizational collaboration through fast and cheap customization and integration of existing services. Prior studies have suggested that using mashups is a viable solution for collaborative work where participants need personalized tools to create, share, and present information (Anjomshoaa et al. 2009; Soriano et al. 2010).

The impact of emerging technologies on organizational forms and functions can be significant (Zammuto et al. 2007; Garrigos-Simon et al. 2012). Traditional ways to plan, execute, collaborate, and manage activities in organizations are changing. A substantial amount of research in this area has been done over the past decennia. Generally, three streams of research can be identified.

The first stream of studies discusses whether emerging technologies are beneficial to organizations. While technology vendors typically claim advantages, such as improved productivity, knowledge retention, fostering innovation, and delivering competitive advantage, research findings often reveal a complicated picture. For example, Denyer et al.'s (2011) case study of a large company found that integrated Web 2.0 technologies (e.g., blogs, podcasts, RSSs, wiki) merely acted as alternatives to existing communication channels and reinforced existing organization dynamics, not delivering significant organizational benefits. The authors pointed out that organizational politics might represent a critical barrier. Another study conducted by Hasan and Pfaff (2006) also argued that inappropriate organizational structures might thwart the successful implementation of new technologies.

The second stream of studies tries to explain technology acceptance, adoption, and diffusion. Many theories from different disciplines have been proposed and investigated in this stream of research. For example, in the study of adoption of crowdsourcing, researchers have used theories from strategic, organizational and economic aspects, including strategic 
management theory (Mazzola and Distefano 2010), game theory (Dipalantino and Vojnovic 2009), transaction cost theory (Horton and Chilton 2010), and innovation theory (Trompette et al. 2008).

Finally, researchers from the third stream of studies aim to propose new designs (or modify existing tools) to improve collaborative performance in specific contexts. For example, Vassileva and Sun (2007) used social comparison theory to design a community visualization tool that encourages online community users to engage in responsible and reciprocal contribution behavior. Steinmacher et al. (2016) investigated how a collaborative portal can support newcomers to overcome entry barriers in open source software communities. In a study of wiki-based collaborative learning, $\mathrm{Wu}$ et al. (2013) argued that content history function in the original wiki system provides limited support for knowledge sharing. They designed a dialog box to highlight content changes of an article, which successfully motivated users to contribute.

\section{Development of the special issue}

Notwithstanding the wealth of research on collaboration technologies for teams and organizations, it remains a complex challenge to determine what types of technologies can be successfully implemented and how organizations and teams can effectively stimulate their sustained use. As the effective implementation of these technologies in organizations may be domain-dependent and organizational forms, process structures, and cultures differ, a call for increased research from varied contexts and disciplines on the application of advanced collaboration technology in teams and organizations is justified. This special issue of the Information Systems Frontiers journal therefore brings together a collection of papers that report on state-of-the-art research on advanced information technologies to support collaboration in teams or organizations. Each manuscript is an extended version of the best papers presented at the 19th International Conference on Collaboration and Technology (CRIWG) held at Wellington, New Zealand. The CRIWG conferences, initiated in 1995, have become a significant forum for researchers and professionals to exchange ideas and experiences about problems and solutions related to collaboration technology. The focus of the selected papers ranges from systematic reviews and case studies to the design and implementation of tools. Research areas include collaborative learning, crowdsourcing, health, emergency management, social network sites, and collaborative software development.

\section{Papers in the special issue}

Knowing how to successfully embed social interaction services in a collaborative system is crucial for the sustainability of a community. The functions of social services should be monitored and controlled by community managers in order to continually align with users' interests and needs. Gutierrez, Ochoa, Zurita, and Baloian (2016), in their paper entitled Understanding student participation in undergraduate course communities: a case study, aim to determine the effects of user participation and identify suitable strategies of controlling embedded social services (e.g., prestige) to motivate user participation. The authors use undergraduate collaborative course projects as a research context and compare two types of motivation strategies (one emphasizing quality of contributions, the other emphasizing quantity of contributions) against a control (non-motivational) strategy. The results suggest that the two motivation strategies are efficient, although they tend to foster different styles of collaboration to emerge. This study proposes six design suggestions, including reducing participation effort, supporting social representativeness, providing monitoring services, enhancing community governance, and enabling participation awareness. These suggestions are especially useful for software designers who need to embed social services in existing community systems.

Agile methods are designed to meet the dynamic and uncertain environment of software development. Although organizations have increasingly adopted agile methods, collaborative software development dependencies remain a major problem. Since agile development projects are distinctly different from traditional development projects in terms of requirement gathering and team structure and management mechanisms, understanding dependencies is critical. In her paper, $A$ dependency taxonomy for agile software development projects, Strode (2016) proposes a categorization of dependencies and selection of agile software development practices through the analysis of three case studies. Eight types of dependencies (three categories) are identified, including requirements, expertise, historical, task allocation, activity, business process, entity, and technical dependencies. Furthermore, twelve agile practices are identified to address multiple dependencies. These practices can build up an effective minimal set for coordinating a project. This paper offers valuable suggestions to practitioners in choosing appropriate coordination mechanisms to support collaboration in agile software development.

Crowdsourcing is currently attracting much attention from organizations due to its potential to offer competitive advantages by harvesting external knowledge. Yet, the organization of crowdsourcing efforts is complex. It should be based on both managerial factors (e.g., balancing costs and benefits) and design issues (e.g., determining the nature and sequence of activities in the crowdsourcing process). Arguing that managerial factors have not received significant attention from 
researchers, Thuan, Antunes, and Johnstone (2016) present a systematic literature review on the decision to crowdsource in Factors influencing the decision to crowdsource: a systematic literature review. By analyzing 50 relevant papers, the authors identify nine influencing factors and map them into a fourlayer framework (task, people, management, and environment). The authors contend that the proposed framework can act as an actionable guideline for managers to make crowdsourcing decisions.

Mobile phones have an important role in emergency management, as emergency response workers perform mobile computer-supported cooperative work while they are moving to a target location. In the case of firefighters' work, each role requires different information and requirements are constantly evolving. The nature of such emergency management practices requires that mobile applications share a core of common features and also include additional features that can be tailored to each role. For this purpose, a software product line (SPL) becomes a preferred solution. Determining which products become parts of a SPL needs special attention. In their paper, Creating a family of collaborative applications for emergency management in the firefighting sub-domain, Rossel, Herskovic, and Ormeño (2016) extend existing domain analysis processes to apply them to the emergency management domain. The process considers the information related to both emergency and collaboration. Two applications are implemented to confirm the usefulness of the domain analysis processes. This work may receive attention from both SPL domain analysts and emergency management software designers.

Many collaborative learning projects involve students who have different backgrounds (e.g., discipline, culture, and schedules). Student diversity can facilitate the generation of innovative ideas. However, it may also lead to cooperation problems resulting in frustration and disruption. Boundary objects can facilitate collaboration among different knowledge parties by providing a shared reference that is meaningful to all parties. In their paper, Boundary objects in collaborative work and learning, Fominykh, Prasolova-Førland, Divitini, and Petersen (2016) report on a grounded theory study to analyze students' feedback. They present results related to three types of boundary objects (artifacts, discourses, and processes) used in a cross-disciplinary course. For each type, the authors show how the students use the boundary objects and how the students succeed or fail in overcoming boundaries and learning from experience. This exploratory study provides valuable insights for university course designers planning to incorporate a cross-disciplinary collaborative learning project.

At certain stages of therapy (e.g., cognitive behavioral therapy, social competences, and skill training), patients need some autonomy to improve their condition without the need for therapists to be present. Using mobile technology to remotely track a patient's activity is an interesting solution to ensure the success of the therapy. In their paper, designing for geo-referenced in-situ therapeutic scenarios, Duarte and Carriço (2016) discuss the design process of a tool set called InSiThe, which uses geo-referenced data to improve user awareness, allows different forms of group conversations, and provides region-based user tracking. Furthermore, the authors compare the proposed application suite to existing Google-based web services to assess the performance of the proposed tool. The evaluation results show that the proposed integrated approach would be beneficial to the therapeutic process. This paper makes several contributions to therapy support functionalities such as reenactment of patient homework and geographically distributed user monitoring.

In order to cultivate students' "soft skills", many business schools require their students to do collaborative class projects. When students use social services to support their activities, such as Google Maps for collaborative geo-referencing, Twitter and Facebook for communication, and Google Drive for co-editing textual information, they often find these services to be sub-optimal. In their paper, Achieving better usability of software supporting learning activities of large groups, Baloian and Zurita (2016) observe serious problems such as information overload, low usability, and lack of collaboration from students' feedback in a situated learning project. The authors derive functional requirements from both students' feedback and the literature to develop a prototype that offers better usability. Tailored for a specific geocollaborative project, the prototype includes geo-referencing and microblogging functions. The results of a two-semester evaluation confirm that the tailored prototype application is superior to online free social media services such as Google Maps. This study demonstrates that standard social media services should not be used directly for organizational collaboration. It serves as an example of the benefits of developing tailored social media services.

Personalized filtering has been widely adopted in social computing systems to deal with overwhelmingly irrelevant social data. While the accuracy of filtering data is important for a filtering system, it often leads to "the filter bubble" problem where users are trapped inside a pool of information that matches pre-stated preferences, without receiving new topics. Furthermore, personalized filtering systems usually do not provide details about the filtering process, resulting in decline of user trust. In their paper, Providing awareness, explanation and control of personalized filtering in a social networking site, Nagulendra and Vassileva (2016) propose a visualization tool with a metaphoric view to alleviate the aforementioned issue. The tool provides awareness (what has been hidden or shown), explanation (why it has been filtered), and control (how to adjust filtering rules) of the personalized filtering process to its users. Three experiments were conducted to test the tool's usability and functionality. The results demonstrate that the proposed visualization offers an effective approach to 
alleviate the filter bubble problem in current social media systems.

To conclude, we would like to thank all participants of the 2013 CRIWG conference. In particular, we would like to thank the authors who submitted their extended papers for consideration to this special issue and the CRIWG 2013 program committee members and reviewers from the Information Systems Frontiers journal. We hope this special issue on Collaboration Technology in Teams and Organizations will engage you in learning recent research in this area and stimulate creativity for your own research efforts.

\section{References}

Almeida, F. L., \& Rocha, R. M. (2011). Introduction of a wiki in an enterprise: Motives and challenges. Journal of Systems Integration, 2(4), 46-53.

Andriole, S. J. (2010). Business impact of web 2.0 technologies. Communications of the ACM, 53(12), 67-79.

Anjomshoaa, A., Bader, G., \& Tjoa, A. M. 2009. Exploiting mashup architecture in business use cases. In International Conference on Network-Based Information Systems (pp. xx-xxvii). Indianapolis, USA: IEEE.

Arazy, O., \& Gellatly, I. R. (2012). Corporate wikis: The effects of owners' motivation and behavior on group members' engagement. Journal of Management Information Systems, 29(3), 87-116.

Auinger, A., Ebner, M., Nedbal, D., \& Holzinger, A. (2009). Mixing content and endless collaboration-mashups: Towards future personal learning environments. In Universal access in human-computer interaction. Applications and services (pp. 14-23): Springer.

Bader, G., Anjomshoaa, A., \& Tjoa, A. M. (2012). A context-aware mashup integration guideline for enterprise 2.0. In Multidisciplinary research and practice for information systems (pp. 17-30): Springer.

Baloian, N., \& Zurita, G. (2016). Achieving better usability of software supporting learning activities of large groups. Information Systems Frontiers. doi:10.1007/s10796-015-9580-3.

Bommert, B. (2010). Collaborative innovation in the public sector. International Public Management Review, 11(1), 15-33.

Bonabeau, E. (2009). Decisions 2.0: The power of collective intelligence. MIT Sloan Management Review, 50(2), 45-52.

Brito, J. (2008). Improving government transparency online. Public Manager, 37(1), 22.

Cox, L. P. (2011). Truth in crowdsourcing. IEEE Journal on Security and Privacy, 9(5), 74-76.

Cress, U., \& Kimmerle, J. (2008). A systemic and cognitive view on collaborative knowledge building with wikis. International Journal of Computer-Supported Collaborative Learning, 3(2), $105-122$.

Denyer, D., Parry, E., \& Flowers, P. (2011). "Social”, “open” and "participative"? Exploring personal experiences and organisational effects of enterprise2.0 use. Long Range Planning, 44(5-6), 375-396.

DiPalantino, D., \& Vojnovic, M. (2009). Paper presented at the Proceedings of the 10th ACM conference on Electronic commerce. Stanford, California: USA. crowdsourcing and all-pay auctions.

Duarte, L., \& Carriço, L. (2016). Designing for geo-referenced in-situ therapeutic scenarios. Information Systems Frontiers. doi:10.1007/ s10796-015-9576-z.
Fominykh, M., Prasolova-Førland, E., Divitini, M., \& Petersen, S. A. (2016). Boundary objects in collaborative work and learning. Information Systems Frontiers. doi:10.1007/s10796-015-9579-9.

Garrigos-Simon, F. J., Lapiedra Alcamí, R., \& Barberá Ribera, T. (2012). Social networks and web 3.0: Their impact on the management and marketing of organizations. Management Decision, 50(10), 1880 1890.

Go, E., \& You, K. H. (2016). But not all social media are the same: Analyzing organizations' social media usage patterns. Telematics and Informatics, 33(1), 176-186.

Gutierrez, F. J., Ochoa, S. F., Zurita, G., \& Baloian, N. (2016). Understanding student participation in undergraduate course communities: A case study. Information Systems Frontiers. doi:10.1007/ s10796-015-9573-2.

Hasan, H., \& Pfaff, C. C. (2006). The wiki: An environment to revolutionise employees' interaction with corporate knowledge. In Proceedings of the 18th Australia conference on ComputerHuman Interaction: Design: Activities, Artefacts and Environments (pp. 377-380): ACM.

Hong, D., Suh, E., \& Koo, C. (2011). Developing strategies for overcoming barriers to knowledge sharing based on conversational knowledge management: A case study of a financial company. Expert Systems with Applications, 38(12), 14417-14427.

Horton, J. J., \& Chilton, L. B. (2010). The labor economics of paid crowdsourcing. In Proceedings of the 11th ACM conference on Electronic commerce (pp. 209-218). New York: ACM.

Howe, J. (2008). Crowdsourcing: Why the power of the crowd is driving the future of business. New York: Crown Business.

Lin, F.-R., \& Hsueh, C.-M. (2006). Knowledge map creation and maintenance for virtual communities of practice. Information Processing \& Management, 42(2), 551-568.

Majchrzak, A., \& Malhotra, A. (2013). Towards an information systems perspective and research agenda on crowdsourcing for innovation. The Journal of Strategic Information Systems, 22(4), 257-268.

Mazzola, D., \& Distefano, A. (2010). Crowdsourcing and the participation process for problem solving: The case of bp. In Proceedings of ItAIS 2010 VII Conference of the Italian Chapter of AIS (pp. 42-49): Napoles: ItAIS.

Nagulendra, S., \& Vassileva, J. (2016). Providing awareness, explanation and control of personalized filtering in a social networking site. Information Systems Frontiers. doi:10.1007/s10796-015-9577-y.

Oh, O., Nguyen, C., de Vreede, G.-J., \& Derrick, D. C. (2012). Collaboration science in the age of social media: A crowdsourcing view. In Proceedings of Group Decision \& Negotiation 2012, Recife, Brazil.

Pedersen, J., Kocsis, D., Tripathi, A., Tarrell, A., Weerakoon, A., Tahmasbi, N., et al. (2013). Conceptual foundations of crowdsourcing: A review of is research. In Proceedings of the 46th Hawaiian International Conference on System Science (pp. 579-588). Los Alamitos: IEEE Computer Society Press.

Rossel, P. O., Herskovic, V., \& Ormeño, E. (2016). Creating a family of collaborative applications for emergency management in the firefighting sub-domain. Information Systems Frontiers. doi:10. 1007/s10796-015-9575-0.

Seyff, N., Todoran, I., Caluser, K., Singer, L., \& Glinz, M. (2015). Using popular social network sites to support requirements elicitation, prioritization and negotiation. Journal of Internet Services and Applications, 6(1), 7.

Soriano, J., Lizcano, D., Cañas, M. A., Reyes, M., \& Hierro, J. J. (2010). Enabling innovation across the enterprise through mashup-oriented collaboration environments. International Transactions on Systems Science and Applications, 6(1), 423-451.

Standing, C., \& Kiniti, S. (2011). How can organizations use wikis for innovation? Technovation, 31(7), 287-295.

Steinmacher, I., Conte, T., Treude, C., \& Gerosa, M. A. (2016). Overcoming open source project entry barriers with a portal for 
newcomers. In Proceedings of the 38th International Conference on Software Engineering, Austin, TX Forthcoming.

Storey, M.-A., Cheng, L.-T., Bull, I., \& Rigby, P. (2006). Shared waypoints and social tagging to support collaboration in software development. In Proceedings of the 2006 20th anniversary conference on Computer supported cooperative work (pp. 195-198): ACM.

Strode, D. E. (2016). A dependency taxonomy for agile software development projects. Information Systems Frontiers. doi:10.1007/ s10796-015-9574-1.

Thuan, N. H., Antunes, P., \& Johnstone, D. (2016). Factors influencing the decision to crowdsource: A systematic literature review. Information Systems Frontiers. doi:10.1007/s10796-015-9578-x.

Trompette, P., Chanal, V., \& Pelissier, C. (2008). Crowdsourcing as a way to access external knowledge for innovation. In 24 th EGOS Colloquium, Amsterdam, France.

Van Osch, W., Steinfield, C. W., \& Balogh, B. Enterprise social media: Challenges and opportunities for organizational communication and collaboration. In 2015 48th Hawaii International Conference on System Sciences (HICSS), Hawaii, 2015 (pp. 763-772). Los Alamitos: IEEE Computer Society.

Vassileva, J., \& Sun, L. (2007). Using community visualization to stimulate participation in online communities. E-Service Journal, 6(1), 3-39.

Vivacqua, A. S., \& Borges, M. R. S. (2012). Taking advantage of collective knowledge in emergency response systems. Journal of Network and Computer Applications, 35(1), 189-198.

Wu, K., Vassileva, J., Zhu, Q., Fang, H., \& Tan, X. (2013). Supporting group collaboration in wiki by increasing the awareness of task conflict. Aslib Proceedings: New Information Perspectives, 65, 581-604.

$\mathrm{Wu}$, L. (2013). Social network effects on productivity and job security: Evidence from the adoption of a social networking tool. Information Systems Research, 24(1), 30-51, doi:doi:10.1287/isre.1120.0465.

Zammuto, R. F., Griffith, T. L., Majchrzak, A., Dougherty, D. J., \& Faraj, S. (2007). Information technology and the changing fabric of organization. Organization Science, 18(5), 749-762.

Zhao, Y., \& Zhu, Q. (2012). Evaluation on crowdsourcing research: Current status and future direction. Information Systems Frontiers, 16(3), 417-434.

Gert-Jan de Vreede is a Professor at the Information Systems and Decision Sciences Department of the University of South Florida. He received his $\mathrm{PhD}$ from the Faculty of Technology, Policy and Management of Delft University of Technology in the Netherlands. His research focuses on crowdsourcing, Collaboration Engineering, convergence, and the facilitation of group meetings. His research has appeared in journals such as Journal of Management Information Systems,
Management Information Systems Quarterly Executive, Journal of the Association for Information Systems, Communications of the Association for Information Systems, Small Group Research, Communications of the ACM, and Group Decision and Negotiation. He was named the most productive Group Support Systems researcher worldwide from 2000 to 2005 in a comprehensive research profiling study.

Pedro Antunes is Associate Professor at Victoria University of Wellington, School of Information Management. He has a Ph.D. in Electrical and Computer Engineering from the Technical University of Lisbon and Habilitation in Informatics Engineering from the University of Lisbon. Pedro's research is mainly focused on human/organizational facets of decision support and business process management systems. Pedro has published articles in ACM Computing Surveys, Behavior and Information Technology, Information Systems Frontiers, IEEE Pervasive Computing, IEEE Transactions on System, Man, and Cybernetics, Journal of Systems and Software, Expert Systems With Applications, Group Decision and Negotiation, and other journals. Pedro is currently Associate Editor at IEEE Transactions on Human-Machine Systems.

Julita Vassileva is a Professor at the Computer Science Department at the University of Saskatchewan. Her research is in the area of user modeling, adaptation and personalization, trust and reputation systems, persuasion and behavior change technologies and intelligent tutoring. She has published over 180 academic papers with her students and is a member of the editorial boards of User Modeling and User Adaptive Interaction, IEEE Transactions of Learning Technologies, Computational Intelligence and PeerJ Computer Science.

Marco Aurélio Gerosa is an Associate Professor at the Computer Science Department at the University of São Paulo, Brazil. His research lies in the intersection between Software Engineering and Social Computing, focusing on the fields of empirical software engineering, mining software repositories, software evolution, and social dimensions of software development. He receives a productivity fellowship from the Brazilian Council for Scientific and Technological Development and coordinates award-winning open source projects. For more information, visit http://www.ime.usp.br/ gerosa.

Kewen Wu is a Postdoctoral Fellow at the Computer Science Department at the University of Saskatchewan. His research is in the area of online community and electronic commerce. His research has appeared in journals such as International Journal of Information Management, Online Information Review, Aslib Journal of Information Management, Journal of Retailing and Consumer Services and Journal of Trust Management. He has also presented his work in conferences such as the CRIWG, PACIS and iConference. 